\title{
Teachers' innovative change within countrywide reform: a case study in Rwanda
}

\author{
Alphonse Uworwabayeho
}

Published online: 15 October 2009

(C) The Author(s) 2009. This article is published with open access at Springerlink.com

\begin{abstract}
This article presents practical perspectives on mathematics teacher change through results of collaborative research with two mathematics secondary school teachers in order to improve the teaching and learning of mathematics in Rwanda. The 2006 national mathematics curriculum reform stresses pedagogies that enhance problemsolving, critical thinking and argumentation. Teachers need to use new teaching strategies. This article is a case study looking at issues around developing teachers' use of interactions in mathematics classrooms independently of the national programme. Outputs of the study include teachers' awareness of the need for change and their increased flexibility to accept learners' autonomy in shifting from teacher-centred to learner-centred pedagogy. Geometer's Sketchpad challenged teachers' practice and then provoked reflection to improve student learning.
\end{abstract}

Keywords Teacher's change - Classroom interactions · Self-reflection · Geometer's sketchpad · Collaborative action · Learners' creativity

\section{Background}

Rwandan formal education is a recent phenomenon, going back less than a hundred years and originally being under the missionaries' administration. My own widespread classroom observations show striking similarity of practice: mathematics teachers explain concepts while writing notes on the chalkboard and learners copy notes into their notebooks. For the last 5 to $10 \mathrm{~min}$ of a lesson learners practise taught techniques through working on prescribed exercise questions. This notion of education as 'chalk and talk' has taken root in society more widely. However, such pedagogy is generally in opposition with the 2006 Rwandan national mathematics curriculum that emphasises improving learners' critical

A. Uworwabayeho $(\square)$

Kigali Institute of Education, Kigali, Rwanda

e-mail: rwabayeho@yahoo.fr

A. Uworwabayeho

University of Bristol, Bristol, UK 
and problem-solving skills. The dominant approach to teaching needs to change if Rwanda is to realise its vision to transform into a knowledge-based economy; such change is complex.

This article is a case study of the effect on two teacher's practices of introducing dynamic geometry software (DGS) in the context of the strongly embedded culture of rote learning found in Rwandan schools. The aim of the project which led to this article was to enhance teachers' self-reflection on their teaching towards improving classroom interaction. So the mediating effect of the DGS was aimed at supporting the teachers.

\section{Theoretical framework}

My research draws on socio cultural theory and foregrounds learning as mediated action by both social and cultural tools (Wertsch 1991). Lave (1996) argues that learning as it normally occurs is a function of the activity, context and culture in which it occurs (situated learning). Hence learning is a community practice, not an individual enterprise. "Learning is culturally shaped: people develop their understandings of any enterprise from their participation in the community of practice within which that enterprise is practised" (Schoenfeld 1992, p. 22).

Previous research studies (e.g. Trouche 2003; Laborde 2002) have shown how tools afford changes in learning and teaching but also observe that the integration of technology into teaching constitutes a long process. The learning potential of a new technology emerges in the classroom as a complex interrelationship of the designer's and teacher's intentions, the teacher's and students' perceptions of how the technology can be used, and the cultural context (John and Sutherland 2005). In order to make sense of the case study, I now offer more detail of the cultural context of mathematics education in Rwanda.

\section{An overview of Rwandan mathematics education}

Formal education in Rwanda was introduced around 1900. The formal education system is composed of pre-primary or nursery schools (pupils aged 3-7), primary schools (7-13), secondary (13-19) and universities. It is the ministry of education (MINEDUC) that leads general policy. From a school administrative standpoint, there are three types of schools: state owned, semi-independent (mostly owned by the church) and private (individual associations). There are approximately 2,500 schools in Rwanda (2,000 primary and 500 secondary) in 2005. At present, the pre-primary education is still informal; schools are constructed and managed under parents' initiatives.

Primary education is compulsory and state schools are free for all children. Secondary education is provided in two levels: the first level made up of 3 years (children 13-17 years old) known as lower secondary school and the second level also known as advanced level or A level for 3 years (pupils 17-19 years old). Transitions from primary to secondary level and from lower to advanced levels are subject to passing national examination. Pupils are introduced to numeracy and literacy in primary schools. At the lower level, all students have the same timetable and learn the same subjects with mathematics occupying $6 \mathrm{~h}$ a week. At the advanced level, students are clustered into different subjects including mathematics-physics and biology-chemistry, so called scientific subjects. The clustering into different subjects is generally based on learners' preference and their performance in national examination. 
Secondary public (state and semi-independent) schools are cheaper than private ones in terms of school fees. So, the entrance to public schools is based on a national examination. It is probably worth noting that the national examination at the end of the 6 years of primary education pushes the majority of children (12-13 years old) out of the education system because only a few places are available in public secondary schools. For example, the statistics for the academic years 2007 and 2008 show that only 8.1 and $14.9 \%$ of the candidates who sat for the examinations were admitted in public schools (RNEC report). ${ }^{1}$ The rate at which pupils leave schools at such an early age is one of the motivations to include the lower level of secondary in primary education and hence make it compulsory; so the duration of primary education which used to be 6 years is being extending up to 9 years in line with the stated aim of education for all by 2015 .

Almost all teachers in primary schools are qualified but secondary schools still have serious problems since most of the teachers are not qualified. Statistical data for 2001/2 shows that the percentage of qualified mathematics teachers was $51.9 \%$ in secondary schools $^{2}$ (MINEDUC, 2003). In 1998, trying to sort out this persistent shortage, the government established the Kigali Institute of Education as a specialist degree awarding institution to educate prospective secondary school teachers and tutors for teacher training colleges.

Although mathematics as a subject is given priority in line with Rwanda's vision of building a knowledge-based economy, there are less students studying mathematics at advanced level and university levels compared with other subjects such as humanities and arts. There is a high failure rate of students in national mathematics examinations at all levels (MINEDUC 2003). For example, from the population finishing the lower level in the academic year 2003/2004, only $20.8 \%$ was enrolled in scientific subjects at advanced level. The average marks in Mathematics were 44.43 and 38.79\% in 2007 and 2008, respectively, in national examination at the ordinary level. The average marks were $10.72 \%$ for those who completed the advanced level of the Mathematics-Physics subject in 2007 (RNEC report). It is not possible to compare Rwanda's mathematics performance with other countries since there is little if any participation of Rwandan students in regional or international mathematics tests.

The failure rate, or non attendance, in scientific subjects has been attributed to the lack of qualified mathematics teachers and inadequate facilities such as learning resources in schools. But there is anecdotal evidence that even qualified teachers continue to promote rote learning for reasons that include class size, content-laden curriculum, lack of continuing education and overloaded working hours per teacher; there is an average of 30 weekly classroom working hours for a teacher with class sizes of about 45 learners.

\section{Context of the case study: the EdQual-RPC project}

EdQual is a Research Programme Consortium consisting of six Universities (from Africa and the UK) focused on "Implementing Education Quality" in low income countries, funded by the UK's Department for International Development for the period 2005-2010. EdQual-ICT attempts to analyse the status of infrastructures and the use of ICT in teaching and learning mathematics and sciences in Rwanda and South Africa to improve education

\footnotetext{
${ }_{1}$ RNEC stands for Rwanda National Examination Council.

2 The national framework profile considers as qualified secondary school teachers any owner of an undergraduate degree with pedagogy from a recognised institution of higher education.
} 
quality, while EdQual-ICC seeks to identify the best ways to implement mathematics and sciences curricula (for further details see www.edqual.org).

In the EdQual project, teachers and learners in twelve Rwandan partner schools started using computers for teaching and learning, especially mathematics and sciences. Teachers in these schools say that the EdQual initiatives have helped to reduce the challenges related to learners' computer illiteracy and therefore motivation in the use of computers for teaching and learning in other subjects. At the November 2007 workshop, it was shown that collaborative action research positively changed teacher's attitudes towards the use of ICT and created awareness and curiosity in learners to explore computers for learning rather than only playing games. The most frequent uses are spreadsheets and power point presentations in mathematics lessons.

My role within EdQual is to build links between academic researchers (national as well as international) and teachers from partner schools as well as following up the implementation of the EdQual aims and research processes.

The research is predicated on the view that the use of new technologies such as Dynamic Geometry Software (DGS) could enhance the teaching and learning of mathematics given the willingness of teachers to adapt their pedagogical approaches. This is within the context of "ICT in basic education" and the "Implementation of Curriculum Change", two components of the EdQual project that relate to Rwandan views that consider ICT as an important tool for building the country's prosperity, alleviating poverty and promoting gender equity. The Government of the Republic of Rwanda, through the ministry of education and specific donors, have gone a step further to equip schools with the computers and train some teachers in the basics of computers. In order to select partner schools, the EdQual organised school visits in the months of March-April 2006 and August-September 2007 in 30 different schools across the country. These visits were conducted to find out the status of ICT infrastructure and its use in schools. It was observed that the average school size was about 600, learners and personnel included. The number of computers varies from 10 to 46 computers per school at secondary level and less than 3 at primary level. Few primary schools have access to electricity. Though the number of computers is increasing especially in private schools, all schools share the lack of maintenance. This provision is not adequate and the real challenge lies in addressing the rising needs of the young learners and teachers in the schools. Interviews with focus groups of learners in the twelve partner schools revealed that quite a number of them have personal experiences of using computers outside school, mainly in internet cafés, and the tasks they are involved in are creative. In one interview conducted with a focus group (year 3 of lower secondary level/grade 9), when asked about the benefits of computers, a learner (girl) pointed out that computers enhance their curiosity, 'through using computers you discover other things and this makes you curious to keep trying and then you learn much more'.

Does new technology catalyse teachers' change by enhancing classroom interactions? What is happening in computer-assisted classrooms is encouraging but somehow contradictory.

On the one hand, teachers and learners appreciate the use of ICT in the teaching and learning of mathematics. Learners' participation in computer-assisted lessons taught is said to be very high compared to the traditional lessons without computer. This was echoed in an interview with one of the teachers after a computer assisted lesson on graphing of linear functions. 'Learners participate more when using the computer. [...] Using computers saves time. This lesson would take $2 \mathrm{~h}$ but with the computer, it has been possible to teach it in 45 minutes, even all the students doing the exercises [...]'. 
On the other hand, classroom observations showed that technology is still mainly used to support the teaching rather than the learning which remains a fundamentally teachercentred conception of teaching. As the teacher stated in the above quotation, it was observed that teachers cover a lot of material in a short time because the overall lesson plan and delivery remain the same as those described earlier; the only difference being in the last stage, where learners type answers into computers.

\section{Willingness to and evidence of change}

The research was conducted in one of partner schools of the larger scale EdQual project. The school is a mixed secondary school with a population of about 950 students, 43 teachers in 2008 , located in the capital city and receiving among the best primary school leavers. The average class size in this school is 30 . They have about 40 computers all linked together forming a network in the same room as a smart board, projector, scanner and Internet; all donated by the New Partnership for African Development (NEPAD) e-school initiative in November 2005. Compared to other Rwandan schools of this size, this is not an unusual number of computers to have, but there is a significantly lower class size than in most schools, as a result of school's intention to excel. The computer room is open for teachers but not for unsupervised learners.

Two mathematics teachers (Isaie and Laetitia) were already involved in EdQual and participated in this particular study which focuses on the use of Geometers' Sketchpad (GSP) from May 2008 until June 2009. They teach mathematics in senior two/grade 8 and senior three/grade 9 at ordinary level. The teachers are certified from two different institutions of higher learning for teaching Mathematics and Physics at secondary level and have 2 and 3 years experience, respectively.

Initially, to avoid interfering with the school calendar, the teaching experiment was included in the usual teaching process but as time elapsed, the computer room was used by either the administration for community development of professionals or for learners' computer skills lessons. We needed to organise class activities in extra ordinary periods; that is in hours not normally reserved for teaching. During our sessions, learners had to sit in pairs at a computer and were called upon to share and discuss their views. This is an unusual situation in Rwandan classrooms where teachers usually stand in front of the class and talk and learners talk only to answer teacher's questions or ask clarifications.

The overall collaborative action was based on teacher-researcher meetings during teachers' break time and teaching in the school. Prior to the classroom activities, three meetings of about $1 \mathrm{~h}$ each were organised. These meetings were devoted to explaining the purpose of the research and the role of each participant since the process is quite different from the usual ones in the larger project. We discussed topics to be taught, considering the national mathematics curriculum and generally we jointly planned and co-taught as much as conditions allowed. (Sometimes one teacher was busy teaching his/her class). There were often two or three teachers in the same classroom. Each teacher had previously used a spreadsheet at least once in his/her class.

Over the period of the research, there were meetings or telephone conversations. Initially, we had planned to have $1 \mathrm{~h}$ a week for classroom activities but the improvised school agenda was not in our favour. We had in total ten meetings and eight classes. Telephone conversations were to confirm whether a given class is due or not while other meetings were to preparing classroom activities. Short meetings, organised after each 
classroom session, were aimed at sharing interpretations of particular events and to develop innovative approaches for future lessons.

During the academic year 2008, we delivered lessons in one of the senior two classes (there were three classes of this grade) and in one class of senior three in 2009. This was deliberately done for two main reasons. First, after introducing the software and objectives of our study to 2008 learners, we wanted to work with the same learners in 2009. Second, we wanted teachers to practise in their usual classes. Unfortunately our first aim was not achieved since the school administration mixed learners at the beginning of the 2009 academic year. Thus some of the 2009 class were not previously introduced to the software. Taking into account this situation we grouped learners (generally in two's or three's) by familiar with non familiar with the Geometer's Sketchpad (GSP).

Given this school description and overall activity organisation, I present the process of change using some classroom stories. This is within collaborative action research already implemented by the EdQual project. Data from this research are composed of researcherteachers discussions during pre-observation and post-observation phases of lessons, and researchers' notes during the lesson. In this case study, there were three significant episodes contributing to the teachers' change.

Findings from students' answers

One classroom observation provoked the awareness that what we, as teachers, take as obvious is not so for learners. During the academic year 2007, Isaie had a lesson on multiplication of integers with senior one learners. During the pre-observation discussions on what strategies to adopt for enhancing critical thinking, problem solving and argumentation skills, we opted for grouping learners in fours. (The normal seating is that two learners share one desk, so two adjacent desks formed one group making a total of eight groups). The task was to discuss properties of multiplication and fifteen minutes were given for this task. Then group representatives simultaneously and silently wrote results on the chalkboard which was divided proportional to the number of groups. Examining properties one after another, the teacher and learners had to decide which group had done the task correctly. Identifying the unit element, three groups were convinced that ' 0 is the identity' while five had said ' 1 is the identity'. Asked to justify their answers, the three groups said 'because 0 is the only identity we have learnt in our last lesson'. (They were referring to addition since the topic came after addition of integers and its properties). At the end of the lesson the teacher expressed surprise how large a number of learners could not easily recognize 1 as unit element.

The teacher was surprised at learners' justifications. He revealed 'since I am teaching I had never given learners opportunity to discuss in their groups. So listening to learners gave me opportunity to know that what I was taking as the easiest thing might be difficult'. Nevertheless at the end of our discussions, the teacher noticed that organizing such group discussions was time consuming even though beneficial. These observations constitute the beginning of teachers' awareness (Mason 1998) and therefore a desire to change their practices aiming to make learners more participative.

Drawing on Lerman (2002) quoting Mason (1998), we hope to work with teachers to educate their awareness so they are sensitised mathematically to work with their students in a mathematically informed and appropriate fashion. Since the Geometer's Sketchpad (GSP) was new tool, I had to introduce its main features to my two colleagues during preparation hours; the challenges of new technologies in general were previously discussed in workshops organised by EdQual. In order to improve collegiality and community 
learning, I taught the two first classes in the presence of the two teachers. I did this partly to familiarise my colleagues with the self-reflection phase to be held after each lesson in this case study.

Before we started our class activities in the GSP environment, I asked learners to construct a square on their sheets. Their construction was mainly based on counting the 'small squares' in their squared sheets. Challenged to explain what they can do if they do not have a squared sheet but only compass and ruler, learners affirmed never having used instruments in constructing geometrical figures.

After the lesson, I asked Isaie how he draws a square on the chalkboard and he confirmed the students' answer: 'I just draw with hands the four sides and assume that it is square, I do not use compass neither ruler'. Concerning geometry, the methodological approach suggested by the national curriculum is that teachers invite learners to construct all geometrical figures using suitable instruments. While constructing a square using geometrical instruments, there is the opportunity to internalise physical properties that include equal and perpendicular sides and right angles. One can observe here that teachers either give little time to explore the curriculum guide or under estimate the importance of the usefulness of the methodological column. (The curriculum starts with general objectives and the rest is presented with three columns of specific objectives, subject content and methodological remarks). GSP was challenging us as teachers to reflect on our practice by using appropriate instruments to construct geometric figures which we have the habit to neglect.

Findings from collaborative action

A powerful experience as repeated by teachers was when I led discussions with their learners. Lave (1996) argues for the social nature of learning based on the premise that human beings are relational, social beings, who of necessity participate and engage with one another. Therefore, learning is a community practice, not an individual enterprise. During a GSP assisted lesson taught by Isaie, I had discussions with learners about whether or not a square is a rectangle. Seventeen learners said no; one said yes and five abstained. The ones who said yes argued that a square is a rectangle because both are polygons.

Drawing on the Aristotle's famous deduction, I asked learners whether or not a human being is an animal in order to bring attention to their conclusion. All learners responded affirmatively.

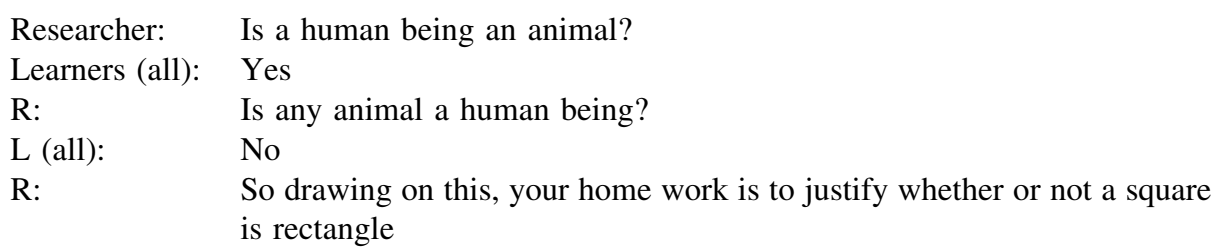

What is important here is not to say that this was the best way of directing learners to the right answer; rather this episode is a simple illustration of the use of our environment and the need for giving time to reflection for our learners instead of staying restricted to mathematical deduction and induction.

Findings from teacher-learner interactions

A pair of learners is inscribing a square in a circle in a lesson taught by the teacher Laetitia. A pair of learners (Christine and Maseka) starts drawing a circle and, using the segment 
menu, constructs a diameter as a segment joining two arbitrary points on the circle but trying to pass through the centre of the circle. They draw another segment intersecting the preceding one approximately at the centre. Finally, they join endpoints of these segments to obtain the following figure (French words mean 'the square constructed by'; learners were asked to write their names on the drawings in order to match with their worksheets during data analysis):

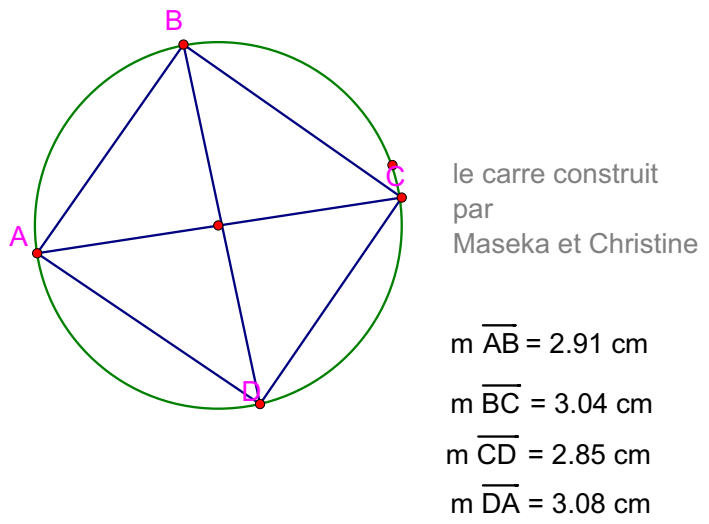

The teacher (L): Is this a square?

Learners: We need to check if the sides are equal?

(Using the "measurement menu" they find sides are not equal)

L: What else can you check?

Learners: Angles

[Measuring angles they find them not all equal and conclude it is not a square]

L: So what can you do to make a square?

(No answer)

L: $\quad$ How do you call these two segments (pointing diameters on the screen)?

Learners: They are diagonals

L: $\quad$ How must be diagonals of a square?

Learners: Oh.... they must be equal

L: $\quad$ Only equal?

Learners: Also perpendicular

L: $\quad$ So now you need to draw perpendicular diameters?

Learners: Yes, but how to do it?

(The teacher explains the process of constructing perpendicular lines and learners carry on.)

After this experience, learners were able to write down in their own words the process used in constructing not only a square but also perpendicular lines.

Teacher-student interactions were facilitated by the dynamic geometry which not only gave learners the opportunity to express themselves and manipulate objects but also helped teachers acquire the habit of asking learners to explain their thinking/doing. In the 
post-observation discussion, the teacher said: 'if I was using chalk and board I could not have a particular attention to any one learner but within the GSP all learners being simultaneously working get direct feedback'. This reveals the awareness of the teacher in relation to the advantages of a learner-centred methodology but the traditional way of teaching does not encourage them to practise it.

\section{Implications}

The GSP environment extends the Silverman and Thompson (2008) question of "what might I do to help students think like what I have in mind" to: "what can I do if students go beyond what I have in mind?" Learners are eager to learn within the dynamic geometry environment. 'With computers it is easier and faster to illustrate something, for example, graphs are clearer than when drawn on a chalkboard...the difference is that when a teacher draws on the chalkboard she might forget something but on the computer we see everything'. This was noted by one of Laetitia's learners in friendly discussions at the end of a GSP-assisted lesson.

The challenge of changing classroom practice to incorporate more discussions and interactions between learners is not straightforward. As well as tensions between the curriculum, the integration of new technologies and the improvement of learner-centred pedagogy in mathematics curriculum, there is also the perspective of learners who for a long time have been chalk and board oriented. During this case study, more general classroom observation showed that few learners' interactions were captured though they were called upon to discuss.

Teachers need time and training to become comfortable themselves with classroom interactions. In addition, teachers are not well acquainted with computers as Isaie says: 'computers have many things that one needs to learn - we need more training on computer skills itself [...]'. Nonetheless he recognised the benefit of GSP in the sense that its features provide enough information so that learners may learn on their own. He expressed, 'I found that my learners have more computer skilfulness'.

Asked whether they will continue to integrate new technologies in their teaching, teachers find it difficult since it is an additional element rather than an integral part of the curriculum. As I mentioned earlier, the third year students have to sit for national examination at the end of year so Laetitia who teaches third years appreciates the effectiveness of interactions with her learners but finds it challenging to implement this approach within current conditions. The teacher identified three major challenges. First, third years have different tests at district level as well as interschool exams in order to prepare them to pass successively national examinations; so we third year teachers are always under pressure to finish the programme early. The non availability of the computer room when mathematics classrooms are due is a second obstacle. Third and last, school policy on the use of computers constitutes another problem that seems to limit learners from utilizing computers in school. Learners have curiosity to use computers but they are only allowed to use the computer room unless under teachers' supervision. Apart from the shortage of enough equipment and maintenance cost there is also a cultural heritage where the family father was the only one to operate simple radios from the 1960s. This suggests that the use of new technologies should be an integral part of the mathematics curriculum. Nevertheless, despite challenges due to computers, Laetitia is determined to promote classroom interactions in her mathematics lessons: 'I need to hear much more from my learners'. 


\section{Conclusion}

Introducing GSP to learners, I took an example of constructing a square. A few minutes later, moving around I found one pair of learners doing it successfully, but differently from the way I showed them. This suggests that once learners are given time to manipulate in an artificial world offered by tools they can be creative. Thus, the DGS potentially shapes learners' knowledge acquisition and changes teacher's inherent habits. What is needed from us teachers is to accept learners' autonomy. However, the teacher's flexibility in accepting learners' autonomy requires confidence in content knowledge as well as pedagogical aptitude. The process of working together seemed to create the awareness in both teachers of their own teaching styles and mobilise them for more self-reliant development. It was also observed that learners are more conversant and experimental in computer assisted lessons compared with the chalkboard environment. The teacher Isaie said: 'one of lessons learnt from this experiment is that the use of questioning in the teaching mathematics made my learners more participative and drew my attention to learners' difficulties'.

In short, the change that has taken place is a development in teachers' awareness towards the improvement of their teaching to enhance classroom interactions rather than teacher's talk and chalk. The use of the GSP provided space for discussions which begin to influence the community of practice in mathematics classrooms. This practice kept not only teachers reflecting on their ways of teaching but also learners getting mathematical exploration skills.

Acknowledgments I would like to acknowledge the following: EdQual project for funding the research; my EdQual colleagues, in Kigali, for their contribution in baseline data collection and transcription; Alf Coles for his advice and observations made during the editing of this article; and the teachers, Laetitia Umutoni and Isaie Gahutu, for their enthusiasm and time.

Open Access This article is distributed under the terms of the Creative Commons Attribution Noncommercial License which permits any noncommercial use, distribution, and reproduction in any medium, provided the original author(s) and source are credited.

\section{References}

John, P., \& Sutherland, R. (2005). Affordance, opportunity and the pedagogical implications of ICT. Educational Review, 57(4), 405-413.

Laborde, C. (2002). Integration of technology in the design of geometry tasks with cabri-geometry. International Journal of Computers for Mathematical Learning, 6(3), 283-317.

Lave, J. (1996). Teaching, as learning, in practice. Mind Culture and Activity, 3(3), 149-163.

Lerman, S. (2002). A review of research perspectives on mathematics teacher education. In F. -L. Lin \& T. Cooney (Eds.), Making sense of mathematics teacher education (pp. 33-52). Dordrecht, The Netherlands: Kluwer Academic Publishers.

Mason, J. (1998). Enabling teachers to be real teachers: necessary levels of awareness and structure of attention. Journal of Mathematics Teacher Education, 1, 243-267.

MINEDUC (2003). Education for all: Plan of action. Kigali: Ministry of Education.

Schoenfeld, A. H. (1992). Learning to think mathematically: Problem solving, metacognition, and sensemaking in mathematics. In D. Grouws (Ed.), Handbook for research on mathematics teaching and learning (pp. 334-370). New York: MacMillan.

Silverman, J., \& Thompson, P. W. (2008). Toward a framework for the development of mathematical knowledge for teaching. Journal of Mathematics Teacher Education, 11, 499-511.

Trouche, L. (2003). From artifact to instrument: mathematics teaching mediated by symbolic calculators. Interacting with Computers, 15(6), 783-800.

Wertsch, J. (1991). Voices of the mind: A sociocultural approach to mediated action. London: Harvester Wheatsheaf. 